\title{
O GERENCIAMENTO DE IMPRESSÃO NO PROCESSO SELETIVO DE CANDIDATOS A VAGAS EM INSTITUIÇÕES FINANCEIRAS NA PERCEPÇÃO DOS GERENTES DE AGẾNCIAS BANCÁRIAS
}

\author{
Guilherme Meyer Oliveira \\ guilherme.meyer.oliveira@gmail.com \\ Centro Universitário Metodista - IPA - RS / Brasil
}

\section{RESUMO}

Desde o momento em que as empresas disponibilizam uma vaga, os candidatos começam a trabalhar no gerenciamento de impressão, que nada mais é do que o candidato se transformar em um produto, em que ele aprende a mostrar para a empresa, o que a empresa quer ver, ou seja, vira um gestor da própria imagem. Deste modo, o estudo discutiu o seguinte problema de pesquisa: como o gerenciamento de impressão auxilia o comportamento dos candidatos a vagas em instituições financeiras, na percepção dos gerentes de agência. Tendo assim como objetivo analisar como o gerenciamento de impressão auxilia o comportamento de candidatos a vagas em instituições financeiras, na percepção dos gerentes de agências bancárias. Apoiou-se nos seguintes objetivos específicos: Identificar os traços de personalidade dos colaboradores escolhidos pelas empresas na percepção dos gerentes; verificar como funciona o processo de recrutamento e seleção em instituições financeiras e apontar as formas de gerenciamento de impressão utilizadas pelos candidatos a vagas em instituições financeiras na percepção dos gerentes. A justificativa da pesquisa baseou-se na concepção atual do mercado de trabalho, onde na visão dos candidatos é cada vez mais competitiva a busca pelo oficio perfeito, onde consiga segurança, estabilidade, motivação e qualidade de vida. Os principais autores utilizados para a discussão foram Chiavenato (2010), Marras 
(2009), Limongi-França (2011), Robbins (2005) e Bittencourt (2010). A metodologia utilizada foi de natureza descritiva, com abordagem qualitativa. Foram sujeitos de pesquisa sete gerentes de agências bancárias de Porto Alegre - RS. A técnica de pesquisa e coleta de dados foi a entrevista com roteiro semiestruturado e um roteiro de observação nas agências visitadas, focando no próprio respondente e no ambiente ao seu redor. A técnica de análise de dados foi a análise interpretativa das respostas, com comparações dos dados pesquisados com o referencial teórico exposto no trabalho. A conclusão deste estudo foi de que todos os candidatos usam do gerenciamento de impressão, consciente ou inconscientemente, para se prepararem para as entrevistas. Cada candidato tentou mostrar suas melhores qualidades, de acordo com a sua percepção e suas experiências passadas, tanto pessoalmente, quanto culturais e sociais. A autopromoção foi a estratégia com maior representatividade; e a concordância e o comportamento não verbal como as táticas mais utilizadas, na visão dos entrevistados sobre os candidatos a vagas em agências bancárias.

PALAVRAS-CHAVE: Gestão de pessoas. Recrutamento. Seleção. Gerenciamento de impressão.

\section{THE MANAGEMENT OF IMPRESS IN THE SELECTIVE PROCESS OF CANDIDATES TO VACANCIES IN FINANCIAL INSTITUTIONS. IN THE PERCEPTION OF BANK AGENCY MANAGERS}

\section{ABSTRACT}

From the moment companies make an empty position, candidates begin to work on impress management, which is nothing more than the candidate turning into a product, in which he learns to show to the company, what the company wants see, that is, become a manager of the image itself. In this way, the study discusses the following research problem: how the impress management assists the behavior of the candidates to positions in financial institutions, in the perception of the agency managers. Aimed at analyzing how impress management helps the behavior of candidates for positions in financial institutions, in the perception of bank branch managers. It presents specific objectives: Identify the personality traits of the employees chosen by the companies in the perception of the managers; to verify how the recruitment and selection process works in financial institutions and to point out the forms of impress management used by the candidates 
O GERENCIAMENTO DE IMPRESSÃO NO PROCESSO SELETIVO

DE CANDIDATOS A VAGAS EM INSTITUIÇÕES FINANCEIRAS

NA PERCEPÇÃO DOS GERENTES DE AGÊNCIAS BANCÁRIAS

to positions in financial institutions in the perception of the managers. The justification of the research is based on the current conception of the labor market, where in the view of the candidates it is increasingly competitive the search for the perfect office, where it achieves security, stability, motivation and quality of life. The main authors used for the discussion were Chiavenato (2010), Marras (2009), Limongi-França (2011), Robbins (2005) and Bittencourt (2010). The methodology used is descriptive in nature, with a qualitative approach. As subjects of research are seven managers of banking branches of Porto Alegre - RS The technique of research and data collection was the interview with semi-structured script and an itinerary of observation in the agencies visited, focusing on the respondent himself and the environment around him. The technique of data analysis was the interpretive analysis of the answers, with comparisons of the data surveyed with the theoretical framework exposed in the work. The conclusion of this study is that all applicants use impress management, consciously or unconsciously, to prepare for the interviews. Each candidate tries to show their best qualities, according to their perception and their past experiences, both personally, as well as cultural and social. Self-promotion was the most representative strategy; and non-verbal agreement and behavior as the most commonly used tactics, in respondents' view of job applicants in bank branches.

KEYWORDS: People management. Recruitment. Selection. Impress management.

\section{INTRODUÇÃO}

No trabalho de administrador são desempenhadas quatro principais funções: planejar, organizar, dirigir e controlar. O objetivo do setor de recursos humanos é ajudar o administrador em questão a executar todas essas atribuições junto à equipe a fim de atingir metas e objetivos previamente traçados. (CHIAVENATO, 2010; MAXIMIANO, 2006).

As instalações físicas, máquinas e equipamentos, recursos financeiros, entre outros, são itens importantes para qualquer organização que planeja um futuro de sucesso, mas o diferencial que a empresa pode ter sobre seus concorrentes está nas pessoas, são elas quem ativam a criatividade para os trabalhos propostos. Os recursos humanos de uma empresa idealizam, 
programam, imaginam, projetam, esboçam e criam produtos e serviços dos mais variados; controlam qualidade, vendem, estipulam metas e objetivos para a sobrevivência e sucesso da organização. (MILKOVICH; BOUDREAU, 2000).

Para que seja possível atingir os objetivos, as empresas criam políticas e ações destinadas a atrair um conjunto de candidatos potencialmente qualificados e capazes de assumir cargos vagos na organização. Tais atividades criadas especialmente para este motivo compõem a função de recrutamento dentro das empresas, que pode ser interno, buscando por profissionais dentro da própria empresa para determinado cargo; ou externo, procurando no mercado por um novo profissional para compor a equipe. (CHIAVENATO, 2010).

O momento seguinte no processo de ter um novo colaborador nas empresas é o da seleção, onde uma organização separa aqueles que se adaptam às necessidades que a empresa está buscando daqueles que não atingem o nível de qualificação para a determinada vaga. (ROTHMANN; COOPER, 2009).

Para que o candidato esteja apto a passar nas diversas fases do processo de recrutamento e seleção e possa vir a se tornar um dos novos colaboradores de determinada empresa, é preciso que ele mostre que é capaz de assumir as responsabilidades que a vaga requer de diversas formas, entre elas, currículo, entrevistas, testes, pesquisas, jogos, entre outras, provando assim, que suas competências o fazem melhor candidato à vaga. (VERGARA, 2006). A fim de mostrar maiores e melhores qualificações para determinada vaga de emprego, o candidato cria um perfil de impressão, onde o pretendente a vaga vira gestor da sua própria pessoa, utilizando táticas e estratégias para se tornar o mais atraente possível aos olhos do entrevistador. (BITENCOURT, 2004).

Assim esta pesquisa objetivou verificar se o gerenciamento de impressão auxilia o comportamento de candidatos 
O GERENCIAMENTO DE IMPRESSÃO NO PROCESSO SELETIVO

DE CANDIDATOS A VAGAS EM INSTITUIÇÕES FINANCEIRAS

NA PERCEPÇÃO DOS GERENTES DE AGÊNCIAS BANCÁRIAS

a vagas em instituições financeiras, na percepção dos gerentes de agências bancárias. Para tal, apoiou-se nos seguintes objetivos específicos: identificar os traços de personalidade dos colaboradores escolhidos pelas empresas na percepção dos gerentes; verificar como funciona o processo de recrutamento e seleção em instituições financeiras e apontar as formas de gerenciamento de impressão utilizadas pelos candidatos a vagas em instituições financeiras na percepção dos gerentes.

\section{REFERENCIAL TEÓRICO}

O segmento da gestão de pessoas, termo corrente em toda e qualquer empresa que sobrevive na atual conjuntura do mercado, é a área que cuida do capital humano, ou seja, das pessoas nas organizações, visando agregar, aplicar, recompensar, desenvolver, manter e monitorar os colaboradores no sentido de enriquecer e capacitar tais pessoas para o auxílio do sucesso da organização. (CHIAVENATO, 2010).

Quando uma organização sente a necessidade de contratação de pessoal é chegado o momento onde precisará ser iniciado um processo de recrutamento e seleção, para que tal vaga seja assumida o mais breve em questão de tempo e melhor em questão de qualidade. Recrutamento de pessoal é a atividade de responsabilidade da administração de recursos humanos que tem por objetivo a captação de recursos, interna ou externamente à organização visando preencher o quadro de possíveis futuros colaboradores, a fim de que estes passem para a próxima fase, que será a seleção. (MARRAS, 2009).

As pessoas que passaram pela fase do recrutamento, que pareceram capacitadas para a vaga em aberto através de diversos instrumentos de análise, avaliação e comparação de dados serão convidadas a continuarem no processo seletivo. (LIMONGI-FRANÇA, 2011). A próxima fase é a seleção de pessoal, etapa que age como um filtro para que, como um funil,

ReMAS • Revista Metodista de Administração do Sul, v. 2, N. 1, 2017 
reste apenas o número certo de candidatos para o determinado número de vagas disponíveis a serem preenchidas. A fase da seleção das pessoas busca pelos profissionais certos, no lugar certo e no tempo certo. (CHIAVENATO, 2010).

O conceito de personalidade é definido como "[...] conjunto de características psicológicas relativamente estáveis que distingue uma pessoa de outra." (GRIFFIN; MOORHEAD, 2006, p. 72). São cinco os itens mais relevantes para a classificação das personalidades dos indivíduos, e alguns outros com menor importância, mas que também interferem no comportamento das pessoas. Sociabilidade, consciência, estabilidade emocional, extroversão e abertura são os cinco principais. Locus de controle, senso de eficiência, autoritarismo, maquiavelismo, autoestima e propensão ao risco são alguns outros. (GRIFFIN; MOORHEAD, 2006).

Existe também o conceito de inteligência emocional, que trata das capacidades que alguns indivíduos têm de lidar com as próprias emoções, controlando-as de acordo com o que necessitam. Autoconsciência, autocontrole, automotivação, empatia e aptidão social fazem parte deste grupo de características que auxiliam na criação da personalidade do individuo (GRIFFIN; MOORHEAD, 2006). O Quadro 1 sintetiza os diversos conceitos sobre traços de personalidade presentes na literatura apresentadas nesta pesquisa. 
O GERENCIAMENTO DE IMPRESSÃO NO PROCESSO SELETIVO

DE CANDIDATOS A VAGAS EM INSTITUIÇÕES FINANCEIRAS

NA PERCEPÇÃO DOS GERENTES DE AGÊNCIAS BANCÁRIAS

Quadro 1 - Conceitos dos traços de personalidade

\begin{tabular}{|c|c|}
\hline \begin{tabular}{|l|} 
TRAÇO DE \\
PERSONALIDADE
\end{tabular} & CONCEITO \\
\hline Sociabilidade & Capacidade de se relacionar bem com os outros. \\
\hline Consciência & $\begin{array}{l}\text { Diz respeito à quantidade de objetivos em que } \\
\text { cada qual é capaz de se concentrar. }\end{array}$ \\
\hline Estabilidade emocional & Variação de humor. \\
\hline \begin{tabular}{|l|} 
Extroversão \\
\end{tabular} & Bem estar nos relacionamentos. \\
\hline Abertura & Maleabilidade das crenças e dos interesses. \\
\hline Lócus de controle & $\begin{array}{l}\text { Indicador de crença das pessoas de que a situação } \\
\text { em que se encontram resulta das suas ações ou } \\
\text { de fatores externos que não conseguem controlar. }\end{array}$ \\
\hline Senso de eficiência & $\begin{array}{l}\text { Confiança na própria capacidade de desempenhar } \\
\text { tarefas. }\end{array}$ \\
\hline Autoritarismo & $\begin{array}{l}\text { Crença de que as diferenças de poder e de status } \\
\text { são corretas em organizações. }\end{array}$ \\
\hline Maquiavelismo & Gostam do poder e de controlar os outros. \\
\hline Autoestima & Consciência do próprio valor. \\
\hline Propensão ao risco & $\begin{array}{l}\text { Grau de disposição de pessoas para tomar deci- } \\
\text { sões arriscadas. }\end{array}$ \\
\hline Autoconsciência & $\begin{array}{l}\text { Capacidade de ter consciência dos próprios sen- } \\
\text { timentos. }\end{array}$ \\
\hline Autocontrole & $\begin{array}{l}\text { Capacidade de equilibrar ansiedade, medo e } \\
\text { raiva. }\end{array}$ \\
\hline Automotivação & $\begin{array}{l}\text { Capacidade de ser otimista e seguir se esforçan- } \\
\text { do mesmo diante de contratempos, obstáculos e } \\
\text { fracassos. }\end{array}$ \\
\hline Empatia & $\begin{array}{l}\text { Capacidade de entender como os outros estão } \\
\text { se sentindo. }\end{array}$ \\
\hline Aptidão social & $\begin{array}{l}\text { Capacidade de se dar bem com os outros e esta- } \\
\text { belecer relacionamentos positivos. }\end{array}$ \\
\hline
\end{tabular}

Fonte: Elaborado pelo autor a partir da bibliografia

Para Bitencourt (2004) o panorama atual mostra que o candidato à determinada vaga precisa se tornar o gestor da sua carreira, trabalhando na sua imagem e conteúdo de forma a agradar ao mercado, destacando as qualidades e caracte-

ReMAS • Revista Metodista de Administração do Sul, v. 2, N. 1, 2017 
rísticas únicas com a intenção de se diferenciar na seleção e num futuro no mercado de trabalho. A operacionalização do gerenciamento de impressão ocorre através de estratégias e táticas; estratégias para impressões de longo prazo e táticas para afetar as de curto prazo.

As estratégias de gerenciamento de impressão são: autopromoção, exemplificação, insinuação, suplicação e intimidação. Enquanto alguns exemplos das táticas podem ser: autodescrição, exclusão, exposição de atitudes, justificativa, entre outras. Os Quadros 2 e 3 sumarizam tais estratégias e táticas (BITENCOURT, 2004).

Quadro 2 - Estratégias de Gerenciamento de Impressão

\begin{tabular}{|c|l|}
\hline ESTRATÉGIAS & \multicolumn{1}{c|}{ DEFINIÇÃO } \\
\hline Autopromoção & $\begin{array}{l}\text { Consiste em demonstrar uma imagem de competência, } \\
\text { destacando as habilidades. Deve-se ter cuidado para } \\
\text { que não se transmita uma imagem de arrogância e } \\
\text { superioridade. }\end{array}$ \\
\hline Exemplificação & $\begin{array}{l}\text { É utilizada para expressar uma imagem de virtudes } \\
\text { morais, como honestidade, lealdade, ética. Indica } \\
\text { cuidados para não se parecer hipócrita ou antipático, ao } \\
\text { querer passar uma imagem de perfeição. }\end{array}$ \\
\hline Insinuação & $\begin{array}{l}\text { É utilizada para ilustrar alguém como amigável e } \\
\text { simpático. Não se trata de um desejo espontâneo de } \\
\text { agradar aos demais, mas de algo feito para se atingir } \\
\text { um objetivo. Deve-se ter cuidado para não parecer } \\
\text { bajulador. }\end{array}$ \\
\hline Suplicação & $\begin{array}{l}\text { Visa transmitir uma imagem de desproteção, de } \\
\text { necessidade de ajuda, para gerar no outro uma resposta } \\
\text { de proteção e auxílio. Implica o risco de incorporar uma } \\
\text { imagem permanente de fraqueza. }\end{array}$ \\
\hline Intimidação & $\begin{array}{l}\text { Consiste em transmitir uma imagem de ameaça e de } \\
\text { agressão, tanto física como verbal. Ao contrario do } \\
\text { desejado, a resposta gerada pode ser de revolta ou } \\
\text { boicote, em vez de submissão. }\end{array}$ \\
\hline
\end{tabular}

Fonte: Bitencourt (2004, p. 363). 
O GERENCIAMENTO DE IMPRESSÃO NO PROCESSO SELETIVO

DE CANDIDATOS A VAGAS EM INSTITUIÇÕES FINANCEIRAS

NA PERCEPÇÃO DOS GERENTES DE AGÊNCIAS BANCÁRIAS

Quadro 3 - Tática de Gerenciamento de Impressão

\begin{tabular}{|c|c|}
\hline TÁTICAS & DEFINIÇÃO \\
\hline Autodescrição & $\begin{array}{l}\text { Consiste em uma forma direta de comunicar algo } \\
\text { sobre si, através de descrições verbais, face a face ou } \\
\text { por escrito. }\end{array}$ \\
\hline Exclusão & $\begin{array}{l}\text { Consiste em omitir certas informações, por julgar } \\
\text { que possam gerar uma má impressão. }\end{array}$ \\
\hline $\begin{array}{l}\text { Exposição de } \\
\text { atitudes }\end{array}$ & $\begin{array}{l}\text { Uma atitude é manifestada com a intenção de gerar } \\
\text { uma determinada impressão. }\end{array}$ \\
\hline Justificativa & $\begin{array}{l}\text { É assumida a responsabilidade do comportamento, } \\
\text { porém se busca apresentar motivos que amenizem } \\
\text { seus aspectos negativos. Pode envolver a } \\
\text { minimização direta, na qual se enfatiza que o evento } \\
\text { não é tão ruim, e a reivindicação de benefício, } \\
\text { quando se justifica que um evento considerado } \\
\text { negativo trouxe algo de positivo. }\end{array}$ \\
\hline Atribuições públicas & É assumida a causa de um evento particular. \\
\hline $\begin{array}{c}\text { Comportamento não } \\
\text { verbal }\end{array}$ & $\begin{array}{l}\text { Inclui a aparência física, gestos e movimentos, e se } \\
\text { refere também as expressões emocionais, ocultando- } \\
\text { as, exagerando ou fingindo, de acordo com a } \\
\text { impressão que deseja causar. }\end{array}$ \\
\hline Associações sociais & $\begin{array}{l}\text { Consiste em se associar a pessoas, fatos e objetos } \\
\text { positivos e dissociar-se dos negativos, ou seja, seguir } \\
\text { o princípio do ditado "Diga-me com quem andar e } \\
\text { direi quem és". }\end{array}$ \\
\hline Concordância & $\begin{array}{l}\text { Concorda-se com os demais, a fim de não haver } \\
\text { rejeição pelo grupo, ou segue-se os outros como } \\
\text { guia, por não saber como agir ou para ter um } \\
\text { desempenho mais efetivo. }\end{array}$ \\
\hline Ambiente físico & $\begin{array}{l}\text { São utilizados objetos decorativos, móveis, diploma, } \\
\text { dentre outros, como meio que oferecem elementos } \\
\text { para serem construídas impressões a seu respeito. }\end{array}$ \\
\hline
\end{tabular}

Fonte: Bitencourt (2004, p. 363).

A seguir se apresenta a metodologia utilizada na pesquisa.

\section{METODOLOGIA}

A abordagem escolhida para esta pesquisa foi a qualitativa e descritiva, que tem como principais características

ReMas - Revista Metodista de Administração do Sul, v. 2, N. 1, 2017 
o uso do ambiente natural do respondente, o contato direto entre pesquisador e entrevistado, mais de uma fonte de dados tais como, entrevista, observações e documentos, criação de padrões de forma indutiva, interpretação do pesquisador de acordo com o que enxerga, ouve, vê e suas próprias experiências (CRESWELL, 2010).

A pesquisa descritiva tem função de observar, registrar, analisar e correlacionar fatores da vida social, profissional, política, econômica e demais áreas do comportamento e atitudes do entrevistado a fim de encontrar ligações com a resolução do problema da pesquisa (CERVO; BERVIAN, 2002).

Os sujeitos foram sete gerentes de agências, de quatro diferentes instituições financeiras privadas na cidade de Porto Alegre, sendo classificados em diferentes cargos dentro de cada organização, pois estiveram presentes nos resultados respostas de gerentes de conta, gerente de agência, gerente de caixa e gerente administrativo. Os critérios de escolha destes sujeitos, para o autor, foram dois: o interesse do pesquisador no perfil das pessoas que convivem no meio do mercado financeiro e acessibilidade a tais instituições na capital gaúcha.

Os instrumentos de coleta de dados utilizados para a realização desta pesquisa foram a entrevista semiestruturada e a observação não participante apoiado em diário de campo, com ambos os instrumentos de coleta elaborados pelo autor.

Depois de coletados os dados, as respostas passaram por análise interpretativa, buscando relações entre as respostas do entrevistado aliados aos conceitos do meio estudado (MARCONI; LAKATOS, 2010).

\section{DISCUSSÃO E ANÀLISE DOS RESULTADOS}

Entre os sete os entrevistados, cinco foram do sexo feminino e dois do sexo masculino. Questionados sobre o curso de sua formação, a maioria dos gerentes respondeu ser graduado 
O GERENCIAMENTO DE IMPRESSÃO NO PROCESSO SELETIVO

DE CANDIDATOS A VAGAS EM INSTITUIÇÕES FINANCEIRAS

NA PERCEPÇÃO DOS GERENTES DE AGÊNCIAS BANCÁRIAS

em Administração, com apenas uma exceção, uma gerente que tem o curso de Letras em seu currículo, com uma pós-graduação em gestão de pessoas. Com relação ao tempo de trabalho na empresa, houve respostas indicando desde três até 29 anos, demonstrando uma variação significativa nesse quesito.

Sobre os traços de personalidade, que mais influenciaram na escolha dos colaboradores pelas empresas, na percepção dos gerentes pesquisados, destacaram-se a automotivação, em primeiro lugar, com cinco dos respondentes afirmando que esta é uma das principais qualidades para um colaborador, entendendo-se aqui que a automotivação na concepção de Griffin e Moorhead (2006) e Robbins (2005b). Na posição seguinte das respostas, surgiu a estabilidade emocional, com quatro respondentes fazendo esta opção, o que mostra o quanto a pessoa precisa estar saudável mentalmente para atingir seus objetivos profissionais. Em terceiro lugar, ocorreram como o mesmo número de respostas a sociabilidade e o autocontrole, com três indicações cada uma.

Sobre recrutamento e seleção os respondentes afirmaram que a sua instituição usa o próprio site como forma de preencher as vagas. No caso, o candidato deve cadastrar o currículo, e quando e se a instituição estiver interessada ela procura o candidato para dar sequência ao processo de recrutamento e posteriormente seleção. A partir do momento que o candidato é convidado a comparecer pessoalmente para a seleção, as instituições diferem na forma como procedem: algumas têm o RH terceirizado e assim outra empresa aplica provas de conhecimento de matemática, língua portuguesa e lógica. Tal ação, segundo Bohlander, Snell e Sherman (2005) comprova a ideia de que a fase da seleção é de grande importância e precisa ser feita por profissionais qualificados e capacitados, para que não ocorram erros, acarretando assim em economia de tempo e dinheiro para a organização. 
Sobre o gerenciamento de impressão, a autopromoção foi a estratégia com maior número de respostas; e a exemplificação a segunda maior assinalada. Para Bitencourt (2004) tais estratégias estão entre as mais destacadas, pois tratam sobre qualidades essenciais para causar uma ótima impressão frente aos entrevistadores. Tais estratégias aparecem no topo da lista também pelo fato de serem as mais fáceis de se trabalhar, sendo basicamente ações que são utilizadas diariamente por provavelmente todas as pessoas, social ou profissionalmente. Mesmo sem a intenção de usá-las, os candidatos, para impressionar seus entrevistadores, muitas vezes mostram-se, mais qualificados do que são.

Sobre as táticas já vistas em candidatos a vagas em agências bancárias a concordância e o comportamento não verbal são as com maior número de indicações pelos gerentes. Segundo Goffman (1985) alguns candidatos que não estão 100\% preparados para passar a imagem que pretendem na entrevista podem cair em "gestos involuntários", assim como apontado pelos gerentes pesquisados sobre a tática de comportamento não verbal que o candidato pode tentar ocultar, exagerar ou fingir expressões ou movimentos, de acordo com a imagem que quer passar. A concordância também foi referida por se tratar de uma tática, segundo Bitencourt (2004), onde o individuo concorda com os demais por não saber como agir ou para ter um desempenho mais efetivo.

Foram quatro os gerentes que apontaram a autopromoção como a estratégia mais positiva dentre as opções. Segundo Bitencourt (2004) trata de passar uma imagem de competência, destacando as habilidades. Ainda de acordo com os gerentes entrevistados a exemplificação ficou em segundo lugar com relação às estratégias positivas mais utilizadas entre os candidatos a vagas, com três indicações. Tal importância se deve ao fato de que essa estratégia, segundo Bitencourt (2004), é 
O GERENCIAMENTO DE IMPRESSÃO NO PROCESSO SELETIVO

DE CANDIDATOS A VAGAS EM INSTITUIÇÕES FINANCEIRAS

NA PERCEPÇÃO DOS GERENTES DE AGÊNCIAS BANCÁRIAS

utilizada para expressar uma imagem de virtudes morais, tais como honestidade, lealdade e ética.

A autodescrição é a tática com maior apontamento pelos gerentes como positiva para os candidatos a vagas em instituições financeiras, que segundo Bitencourt (2004) é a forma direta que o candidato para comunicar algo sobre si. A concordância é a tática negativa mais utilizada pelos candidatos, seguida da justificativa, segundo os gerentes. A primeira, segundo Bitencourt (2004) trata sobre uma pessoa que, ou não tem conhecimentos sobre a questão envolvida; ou não tem certeza suficiente para tomar uma decisão final. A segunda trata de uma pessoa que não tem atitude, que vive dando desculpas para suas falhas, culpando colegas e ou situações que fogem do controle para a não conclusão da atividade com êxito.

\section{CONSIDERAÇÕES FINAIS}

De maneira geral, os gerentes afirmaram que o cadastro do currículo no site da instituição é o primeiro passo para iniciar um processo de seleção; A partir daí seguem diferentes formas de testar o conhecimento e capacidade do candidato, através de provas diversas. A próxima etapa é a do encontro do candidato com entrevistadores treinados, terceirizados ou não, a fim de conhecer melhor o possível futuro colaborador. Segundo respostas dos gerentes de agência entrevistados, o autor concluiu que as principais táticas e estratégias de gerenciamento de impressão utilizadas pelos candidatos a vagas em instituições financeiras são a autopromoção, a concordância e o comportamento não verbal. De acordo com as respostas obtidas nesse estudo foi possível identificar os principais traços de personalidade preferidos para os cargos em agências bancárias foram a sociabilidade, a motivação e a estabilidade emocional.

Inúmeras são as sugestões para pesquisas futuras referentes a temas próximos ao pesquisado neste estudo, inclusive 
com muitos dados secundários já levantados neste trabalho. São exemplos de possíveis futuros estudos, uma pesquisa quantitativa com os próprios candidatos as vagas em instituições financeiras, explorando o lado do candidato, sobre quais táticas e estratégias são preferencialmente utilizadas nas entrevistas. Existe também uma sugestão para uma pesquisa diretamente com os selecionadores das instituições financeiras, visando assim saber o que os selecionadores procuram nos candidatos. É de interesse acadêmico também um estudo sobre como os candidatos a vagas em outros setores trabalham o seu gerenciamento de impressão, ou ainda um estudo acerca dos preconceitos que alguns candidatos, muitas vezes melhor qualificados e capacitados, passam nos processos seletivos por vezes não conseguindo a vaga.

\section{REFERÊNCIAS}

BITENCOURT, Claudia. Gestão contemporânea de pessoas: novas práticas, conceitos tradicionais. 2. ed. Porto Alegre: Bookman, 2004. $528 \mathrm{p}$.

BOHLANDER, George W.; SNELL, Scott; SHERMAN, Arthur. Administração de recursos humanos. São Paulo: Pioneira Thomson Learning, 2005. $547 \mathrm{p}$.

CERVO, Amado Luiz. Metodologia científica. São Paulo: Pearson Prentice Hall, 2002. 242 p.

CHIAVENATO, Idalberto. Gestão de pessoas: o novo papel dos recursos humanos nas organizações. 3. ed. Rio de Janeiro: Elsevier, 2010. 579 p.

CRESWELL, John W. Projeto de pesquisa: métodos qualitativo, quantitativo e misto. Porto Alegre, Artmed, 2010. 296 p.

GOFFMAN, Erving. A representação do eu na vida cotidiana. Petrópolis: Vozes, 1985. 233 p.

GRIFFIN, Ricky; MOORHEAD, Gregory. Fundamentos do comportamento organizacional. São Paulo: Ática, 2006. 488 p. 
O GERENCIAMENTO DE IMPRESSÃO NO PROCESSO SELETIVO DE CANDIDATOS A VAGAS EM INSTITUIÇÕES FINANCEIRAS NA PERCEPÇÃO DOS GERENTES DE AGÊNCIAS BANCÁRIAS

MARCONI, Marina de Andrade; LAKATOS, Eva Maria. Fundamentos de metodologia científica. São Paulo: Atlas, 2005. 315 p.

LIMONGI-FRANÇA, Ana Cristina. Práticas de recursos humanos - PRH: conceitos, ferramentas e procedimentos. São Paulo: Atlas, 2011. 267 p.

MARRAS, Jean Pierre, Administração de recursos humanos: do operacional ao estratégico. 13. ed. São Paulo: Saraiva, 2009. 332 p.

MAXIMIANO, Antonio Cesar Amaru, Teoria geral da administração: da revolução urbana à revolução digital. 6. ed. São Paulo: Atlas, 2006. 488 p.

MILKOVICH, George; BOUDREAU, Jonh W. Administração de recursos humanos. São Paulo: Atlas, 2000. 534 p.

ROBBINS, Stephen Paul. Administração: mudanças e perspectivas. São Paulo: Saraiva, 2005a. 524 p.

Comportamento organizacional. São Paulo: Pearson Prentice Hall, 2005b. 536 p.

ROTHMANN, Ian; COOPER, Cary. Fundamentos da psicologia organizacional e do trabalho. Rio de Janeiro: Elsevier, 2009. 331 p.

VERGARA, Sylvia Constant. Gestão de pessoas. 5. ed. São Paulo: Atlas, 2006. 213 p. 